\title{
Hepatobiliary scintigraphy and its clinical implications: mini review
}

\author{
Muniba Afzal ${ }^{1}$, Syed Muhammad Ali ${ }^{2 *}$, Ahmed Talaat Khairy ${ }^{3}$, Mazin Khattabi ${ }^{2}$, \\ Fakhar Shahid', Ahmed Faidh Ramzee', Khalid Ahmed ${ }^{2}$
}

\author{
${ }^{1}$ Department of Surgery, Hamad Medical corporation, Doha, Qatar \\ ${ }^{2}$ Department of Acute Care Surgery, Hamad Medical corporation, Doha, Qatar \\ ${ }^{3}$ Department of Nuclear Medicine, Hamad Medical Corporation, Doha, Qatar
}

Received: 14 November 2020

Accepted: 30 December 2020

\section{*Correspondence:}

Dr. Syed Muhammad Ali,

E-mail: alismc2051@gmail.com

Copyright: (C) the author(s), publisher and licensee Medip Academy. This is an open-access article distributed under the terms of the Creative Commons Attribution Non-Commercial License, which permits unrestricted non-commercial use, distribution, and reproduction in any medium, provided the original work is properly cited.

\begin{abstract}
The advent of modern investigations like ultrasound and Magnetic Resonance Imaging has completely revolutionized the diagnosis of gallstones and biliary diseases. However, role of biliary scintigraphy has remained pivotal in some of the biliary tract pathologies especially in detecting the functional problems, leaks and bile reflux. HIDA (hepatobiliary iminodiacetic acid) scintigraphy is conventionally used to diagnose these pathologies and not associated with many harmful effects, although it is time consuming. We reviewed this investigation and its utility in detail encompassing the recent evidence and efficacy.
\end{abstract}

Keywords: HIDA scan, Biliary anatomy, Gallbladder

\section{INTRODUCTION}

Hepatobiliary iminodiacetic acid scan (HIDA) or cholescintigraphy is a nuclear medicine procedure used to evaluate health and function of gallbladder and biliary system. A radioactive tracer is injected through any accessible peripheral vein and then it is allowed to circulate to liver from where it is excreted into biliary ducts and stored by the gallbladder until released into the duodenum. A series of images is captured over time with a gamma camera recording 22 -sequence passage of bile.

Most of the radio tracers used for cholescintigraphy are complexes of iminodiacetic acid (IDA) with a radionuclide attached to IDA molecule, which is usually the technetium-99 m. The first and widely used radiotracer compound is HIDA, where " $\mathrm{H}$ " stands for hepatobiliary. The chemical composition of HIDA is dimethyl-IDA. It is not used as much anymore, as other IDA derivatives have progressively replaced it. Examples include PIPIDA (paraisopropyl-IDA), DISIDA (diisopropyl-IDA), BrIDCA (trimethylbromo-IDCA) and
PBIDA (parabutyl-IDA). However, the term HIDA scan is sometimes used even when another other IDA derivatives are used. The radio tracer follows the bilirubin metabolic pathway and then is excreted into the bile ducts, because of this it has proven extremely useful in the diagnosis of various hepatobiliary diseases and in monitoring of bile flow kinetics.

A normal HIDA scan shows very rapid clearance of radio tracer from the blood pool, prompt hepatic uptake and excretion with visualization of activity in gall bladder, common bile duct and small bowel approximately at the same time and usually within the first 10 to 20 minutes (within 1 hour at most).

\section{ANATOMY OF BILIARY TRACT}

The liver produces bile continuously in the hepatocytes and excretes it into small tubular channels called the bile canaliculi. These canaliculi join together to form intralobular and interlobular duct which in turn combine to form the right and left hepatic ducts. The bile flows 
through the right and left hepatic ducts into the common hepatic duct, then through common bile duct and finally into the duodenum. With an intact sphincter of Oddi, bile flow is directed into the gall bladder.

\section{INDICATIONS}

Hepatobiliary scintigraphy evaluates the function of hepatocytes, patency, and integrity of the biliary ducts, gallbladder contractility, and sphincter of Oddi function. The conditions can be evaluated using a hepatobiliary scintigraphy exam include acute and chronic cholecystitis, cholelithiasis, biliary obstruction, leak or atresia, post cholecystectomy syndrome and duodenogastric bile reflux.

\section{ACUTE CHOLECYSTITIS}

\section{Pre-procedure requirements}

Generally, for the diagnosis of acute cholecystitis patients need to be fasting for at least 4 to 6 hours. Fatty food stimulates the secretion of cholecystokinin (CCK) by the cells in duodenum, this causes the contraction of gallbladder and artificially non filling of the gallbladder on the scan. Fasting for 4 to 6 hours allows for complete passage of ingested contents, duodenal CCK secretion stop, and there is relaxation of gall bladder. Alternatively, if patient is fasting for more than 24 hours, it allows gallbladder time to resorb water from bile which thickens the bile and often stops radiotracer to enter gall bladder. This extended fast may lead to a false positive study.

\section{DISCUSSION}

The hallmark of diagnosis of acute cholecystitis on HIDA scan is non-visualization of the gall bladder for up to 4 hours in a patient who was fasting for 4-6 hours.

The absence of radiotracer activity in the gallbladder signal at one hour is abnormal but not specific enough to diagnose acute cholecystitis. At this point, we can acquire delayed imaging after 3+ hours (4+ from administration of radiotracer). However, delayed images are suboptimal in the setting of acute cholecystitis when prompt diagnosis and intervention are preferred. A second, more expeditious option is the administration of a subanalgesic dose of morphine which causes the sphincter of Oddi to contract and the ampulla of Vater to close, this diverts incoming bile to the gallbladder. In a normal patient with a patent cystic duct, filling of the gallbladder will be visible within 30 minutes after morphine administration. This technique allows the completion of the entire exam in 90 minutes. If there is continued nonvisualization of the gallbladder after delayed images or morphine augmentation, this confirms the diagnosis of acute cholecystitis. If gallbladder fills, then acute cholecystitis is excluded. Morphine administration in cholescintigraphy is approximately as accurate as delayed imaging with hepato-biliary scintigraphy (HBS) having a sensitivity of $96 \%$ and specificity of $90 \% .^{1}$

Shea et al looked at tests used in the diagnosis of biliary tract disease and concluded that radionuclide scanning is the test of choice for diagnosing acute cholecystitis. ${ }^{2}$ However, it still remains a second-line test to ultrasound in most circumstances, because it may take 2-4 hours to complete, exposes patient to ionizing radiation, and is more expensive than ultrasound. In addition, it does not directly visualize organs, unlike ultrasound and CT, and so may be less useful in evaluating for alternative pathology. ${ }^{3}$ Another systematic review and meta-analysis of diagnostic performance of imaging in acute cholecystitis done in university of Amsterdam by Kiewiet et al concluded that cholescintigraphy has highest diagnostic accuracy of all imaging modalities in detection of acute cholecystitis. ${ }^{4}$ The diagnostic accuracy of ultrasonography has a considerable margin of error, which is comparable to that of MR imaging.

Kaoutzanis et al evaluated diagnostic imaging workup of 1,217 patients who presented to emergency department at a single hospital with acute abdominal pain and suspicion of acute cholecystitis to calculate the sensitivity and specificity of both HIDA scan and USG Abdomen and concluded that in adult patients undergoing both imaging modalities, HIDA had significantly higher sensitivity (90.7 vs $64.0 \%, \mathrm{p}<0.001)$ and specificity (71.4 vs $58.4 \%$, $\mathrm{p}=0.005)$ than USG for diagnosis of acute cholecystitis. ${ }^{5}$

\section{CHRONIC CHOLECYSTITIS}

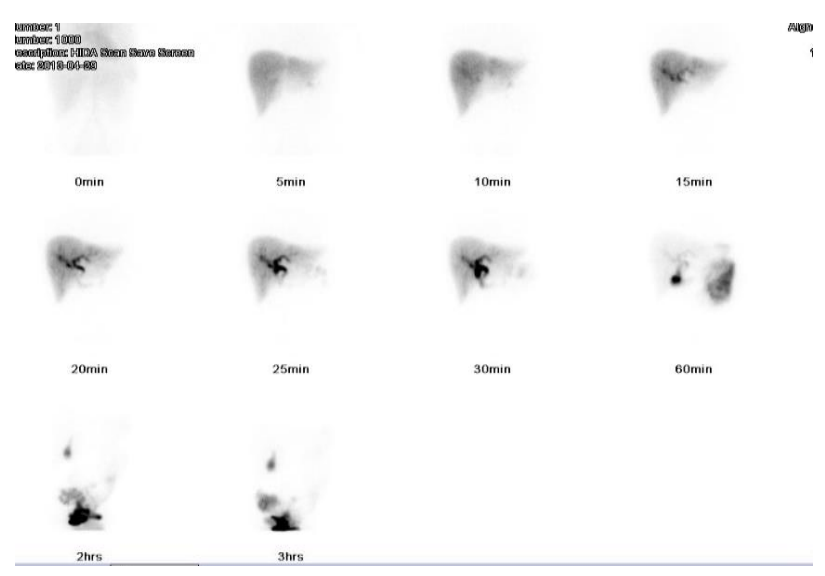

Figure 1: HIDA scan of a 29-year-old female patient who presented with right hypochondrial and right loin pain. Ultrasound revealed no GB contraction after fatty meal. Delayed filling of the gall bladder can be noticed in $60 \mathrm{~min}$ and 2 hours image.

Although not generally used to diagnose chronic cholecystitis, HIDA scan can sometimes show incidental findings which indicate chronic cholecystitis during the course of performing studies for some other pathology. In calculous and acalculous chronic cholecystitis scan shows delayed visualization of the gall bladder, often with 
incomplete filling and decreased emptying with drop in gall bladder ejection fraction. Generally, as the radiotracer bolus fills and exits the common hepatic ducts, it should almost simultaneously fill the GB, CBD, and small bowel. If one of these two routes represents a path of greater resistance, the bile flows preferentially through the other pathway. ${ }^{6}$

\section{BILE REFLUX}

Bile reflux from duodenum to stomach is one of the prime causes of gastritis specially in patients who are status post bariatric surgery of any kind. HIDA scan can be used to evaluate for bile reflux after surgery. Bile reflux was demonstrated in almost $50 \%$ of patients who underwent sleeve gastrectomy, $75 \%$ off those with one anastomosis gastric bypass and $0 \%$ with Roux en $\mathrm{Y}$ gastric bypass. $^{7}$

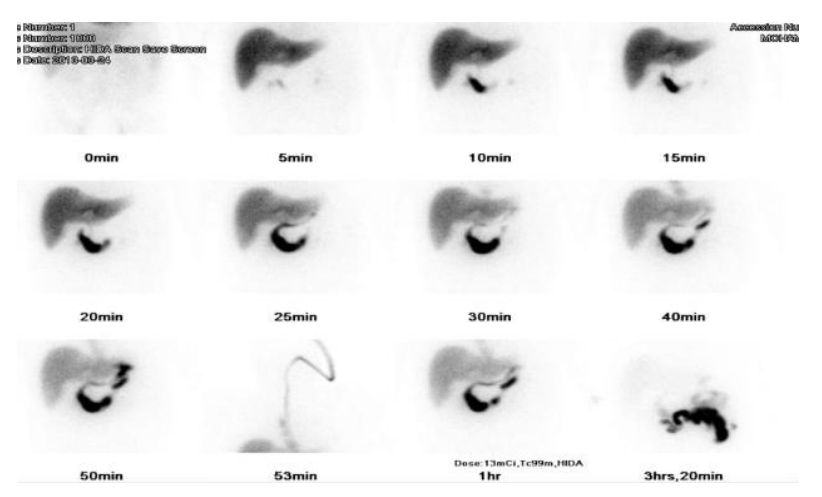

Figure 2: 43-year-old male patient presenting with upper right quadrant abdominal pain. USG revealed fluid collection around gall bladder and under diaphragm. HIDA scan of two abnormalities. The first is the non-visualization of the gall bladder on all images, although the patient was fasting, signifying cystic duct obstruction, i.e., acute cholecystitis. The second abnormal finding is the appearance of the stomach, following tracer arrival to the duodenum, denoting duodeno-gastric bile reflux.

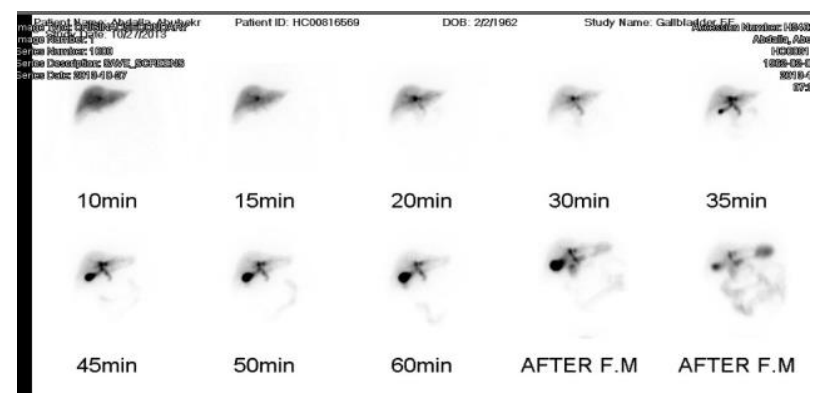

Figure 3: 51-year-old male who came with complaint of right upper quadrant pain-USG only of sludge.

There is visualization of GB at 35-minute scan ruling out acute or chronic cholecystitis although there is visualization of stomach on late images that were taken before and after the fatty meal which indicates bile reflux from the duodenum to the stomach.

\section{BILE LEAKS}

HIDA scan is widely used to diagnose biliary tree injury. It is often the first line investigation along with USG Abdomen. No special patient preparation is required in patients with bile leak undergoing HIDA scan. A biliary leak is diagnosed when radiotracer is identified outside its normal pathway (e.g., outside the liver, biliary tree, and bowel). Most common locations are in the gallbladder fossa (post-cholecystectomy), in the right paracolic gutter or the perihepatic space. In the setting of brisk or large leaks, this may be present during first hour of imaging. Delayed images may be obtained out to 24-hours to identify slow or small leaks. A final delayed image of 3 hours post radiotracer injection is necessary if no major leak is initially noted to confirm absence of a leak.

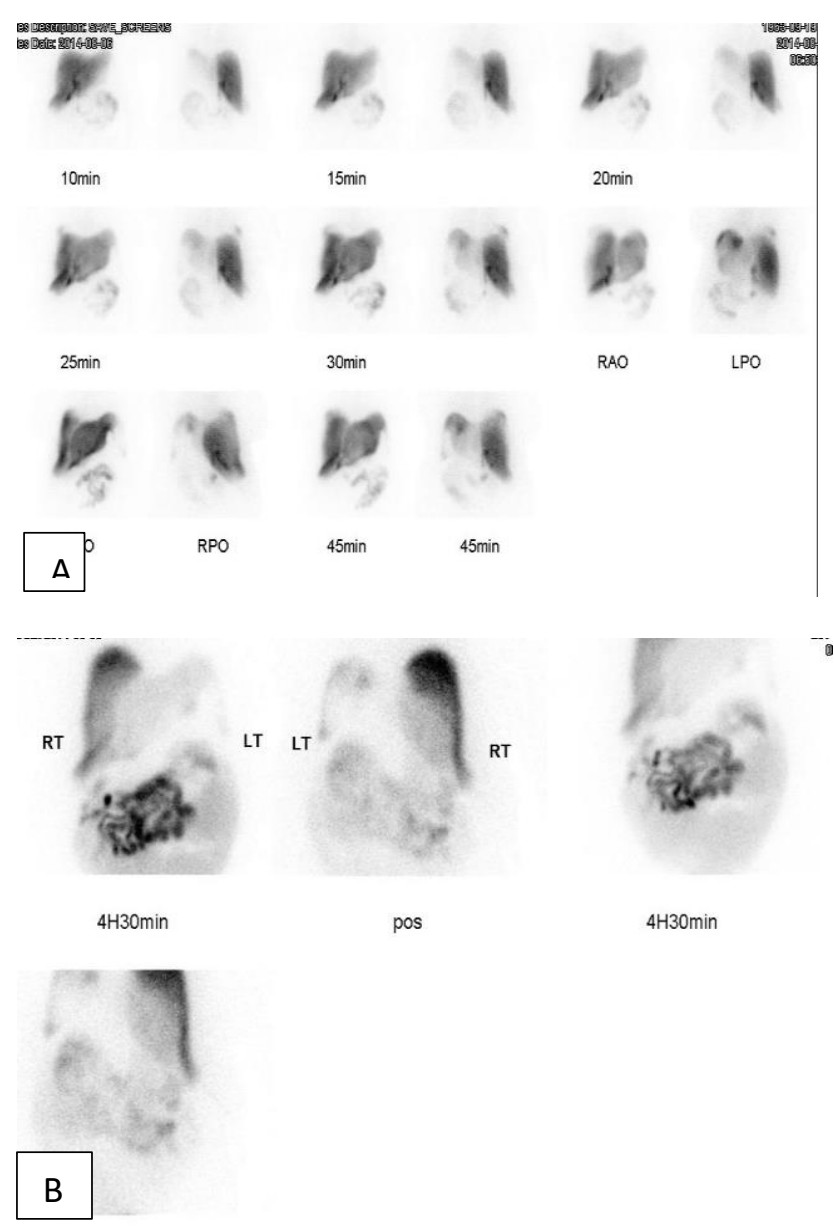

Figure 4: (A) 50-year-old lady who was assessed for bile leak following laparoscopic cholecystectomy.

Simultaneous anterior and posterior views were taken every 5 minutes for $\mathbf{4 5}$ minutes and then delayed images were acquired at 4 hours. (B) The delayed images taken after $\mathbf{4}$ hours of injection for the same patient demonstrated augmentation of the leaked bile into the peritoneal cavity.

In a paper published in 1993, role of cholescintigraphy was evaluated by Brugge et al in-diagnosing complications of laparoscopic cholecystectomy. He 
concluded that after initial screening with USG and $\mathrm{Ct}$ scan, cholescintigraphy could be used to diagnose either the patients without large fluid collections, or when there is a need to determine the response to stenting or surgery. ${ }^{8}$

Naeem et al published a case report in 2015, which described a 16-year-old with history of blunt abdominal trauma. He had central hepatic laceration with extension into gallbladder fossa and peritoneal fluid, who underwent Hepato-biliary scintigraphy (HBS). ${ }^{9}$ The report concluded that although the precise site of a bile leak is often difficult to detect with noninvasive techniques, it is possible with HBS.

Abnormal bile leak was spotted at 20 minutes with a progressive increase in the amount of visualized bile leakage. The bile is seen collecting under the diaphragm above the dome of the liver and along with the surroundings of the liver at both right and left flanks. An abnormal tract of the bile is seen along the inferior aspect of the right hepatic lobe laterally, likely draining the leaked bile from the gallbladder fossa to the peritoneal cavity.

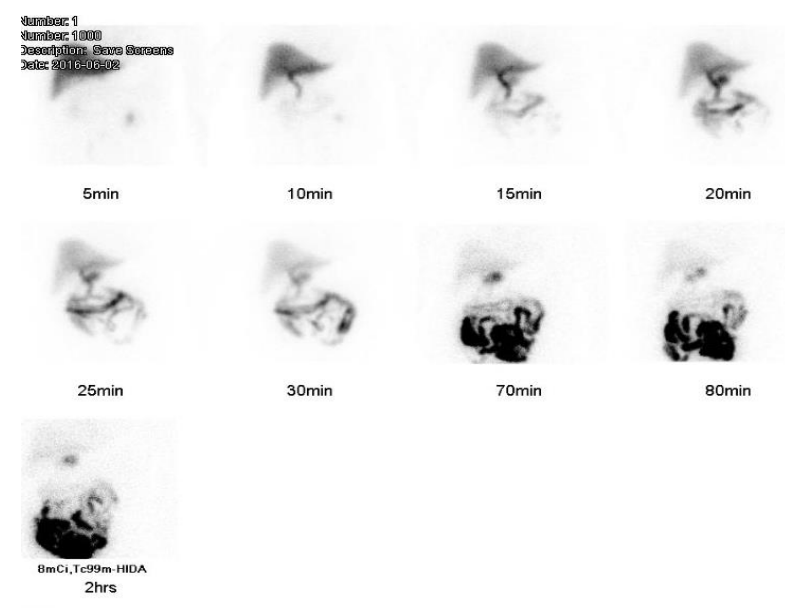

Figure 5: 37-year-old female patient with present history of post-cholecystectomy CBD injury, retroperitoneal hematoma and dilated intra-and extra-hepatic biliary system. HIDA scan shows dilated intra- and extra-hepatic bile ducts with tracer stasis down to the mid to lower segment of the common bile duct. The holdup at that level was sustained up to 1 hour with no tracer arrival to bowel loops by that time.

On the 2 and 4 hours delayed images a cyst-like structure appeared just at medial side of the proximal segment of the common bile duct. This reflects contained bile collection, i.e., biloma.

\section{BILIARY OBSTRUCTION/ATRESIA}

Radionuclide techniques have traditionally been used to differentiate between biliary atresia and neonatal hepatitis in the jaundiced infant. As with the preparation for acute cholecystitis, diagnosis of biliary atresia through HBS also requires fasting of at least 4-6 hours. Phenobarbitalenhanced cholescintigraphy is often used to differentiate neonatal jaundice and biliary atresia. It induces hepatic enzymes, bilirubin conjugation, and excretion. Since the radiotracers follow the same pathway as bilirubin, this preparation step helps reduce the risk of a false-positive results. The recommended dosing regimen is $5 \mathrm{mg} / \mathrm{kg} / \mathrm{day}$ given for five days prior to the scan.

If there is no radiotracer is seen in the bowel during the initial first hour of imaging, there is delayed biliary-tobowel transit is present, which can be due to an obstructive process, although it could also be because of chronic cholecystitis, a normal variant in $20 \%$ of individuals, as well as seen in up to $50 \%$ of patients pretreated with CCK. Delayed images up to 24-hours may be necessary to diagnose obstruction definitively. The degree of obstruction (low-grade/partial versus higrade/complete) can be inferred by the degree of delayed transit and amount of radiotracer reaching to the bowel. Biliary atresia, which is a congenital variant of complete biliary obstruction, is suggested when no radiotracer is seen in the bowel by 24-hours. ${ }^{10}$

In a retrospective study with 46 patients of neonatal cholestasis Shah et al looked at the efficacy of HIDA scan to differentiate between neonatal jaundice and biliary atresia (BA). All patients received phenobarbitone and ursodeoxycholic acid for 5 days, prior to the HIDA scan. ${ }^{11}$ He concluded that $78.6 \%$ patients of BA showed no excretion of the radiotracer at 24 hours whereas only $38.9 \%$ of the neonatal jaundice group did not excrete the radiotracer ( $\mathrm{p}=0.007)$, which was statistically significant. A metanalysis by Kianifar et al with 81 studies using Tc99 m-labeled iminodiacetic acid (IDA) derivatives, evaluated sensitivity and specificity of HIDA scan in diagnosing biliary atresia. ${ }^{12}$ It concluded that pooled sensitivity and specificity were $98.7 \%$ (range 98.199.2\%) and $70.4 \%$ (range 68.5-72.2\%), respectively. Factors that increased specificity included the use of radiotracers with high hepatic extraction, administration of hepatic-inducing drugs (such as phenobarbital), use of a calculated dose $/ \mathrm{kg}$ and administration of a booster dose in cases of non-excretion of the tracer in the bowel.

\section{ERRONEUS RESULTS}

There are a few reasons due to which HIDA scan can give false positive results despite a non-obstructed cystic duct.

Severe liver dysfunction in which there is abnormal uptake and excretion of the liver. This includes severe alcoholic patients as well in which there is hepatic function compromise

Fasting patients (e.g., patients receiving total parental nutrition) have no stimulation to contract the gallbladder. 
In such patients, the gallbladder is already full of viscous bile that prevents the entry of radiotracer.

Patients with biliary sphincterotomy, this could result in low resistance to bile flow, which causes preferential excretion of the tracer into the duodenum directly without first filling gallbladder.

Hyperbilirubinemia can cause false positive as well, since it is associated with impaired hepatic clearance of iminodiacetic acid compounds. This is generally overcome with increasing the dose of radio tracer or using any newer agents (di-isopropyl and mbromotrimethyl iminodiacetic acid)

Shuman et al studied 200 consecutive hospitalized patients with HBS for acute cholecystitis or cholestasis, of which 41 were alcoholics and 17 patients were on total parenteral nutrition. ${ }^{13}$ In $60 \%$ of the alcoholics and $92 \%$ of those on parenteral nutrition, absent or delayed visualization of the gallbladder occurred without physical or clinical evidence of cholecystitis, which is probably because of altered flow of bile due to severe alcoholic hepatic damage and TPN.

\section{CONCLUSION}

Hepatobiliary scintigraphy often answers questions about the pathologies of biliary track which traditionally cannot be answered by other imaging modalities. The ability of radio tracer to be taken up by hepatocytes and excreted along the same pathway as that of bilirubin allows for high sensitivity and specificity in the evaluation of biliary pathologies such as cholecystitis, obstruction or leak and to some extent the assessment of hepatic function.

Funding: No funding sources

Conflict of interest: None declared

Ethical approval: Not required

\section{REFERENCES}

1. Snyder E, Banks KP. Hepatobiliary Scintigraphy. In: StatPearls online. Treasure Island (FL): StatPearls. 2019.

2. Shea JA, Berlin JA, Escarce JJ, Clarke JR, Kinosian BP, Cabana MD et al. Revised estimates of diagnostic test sensitivity and specificity in suspected biliary tract disease. Arch of int med. 1994;154(22):2573-81.
3. Broder J. Imaging of Nontraumatic Abdominal Conditions. Diagnostic Imaging for the Em Phy. 2011;445-577.

4. Kiewiet JJ, Leeuwenburgh MM, Bipat S, Bossuyt PM, Stoker J, Boermeester MA. A systematic review and meta-analysis of diagnostic performance of imaging in acute cholecystitis. Radiol. 2012;264(3):708-20.

5. Kaoutzanis C, Davies E, Leichtle SW, Welch KB, Winter S, Lampman RM, Franz MG, Arneson W. Is hepato-imino-diacetic acid scan a better imaging modality than abdominal ultrasound for diagnosing acute cholecystitis? The Am J of Sur. 2015;210(3):473-82.

6. Chamarthy M, Freeman LM. Hepatobiliary scan findings in chronic cholecystitis. Clin nuc med. 2010;35(4):244-51.

7. Eldredge TA, Bills M, Myers JC, Bartholomeusz D, Kiroff GK, Shenfine J. HIDA and Seek: Challenges of Scintigraphy to Diagnose Bile Reflux PostBariatric Surgery. Obes Sur. 2020;30(5):2038-2045.

8. Brugge WR, Alavi A. Cholescintigraphy in the diagnosis of the complications of laparoscopic cholecystectomy. In Seminars in Ultrasound, CT and MRI. WB Saunders. 1993;14(5):368-74.

9. Naeem S, Li H, Yang Z. Precise localization of a bile leak with hepatobiliary scintigraphy. $\mathrm{J}$ of nuc med tech. 2016;44(1):44-5.

10. Snyder E, Lopez PP. Hepatobiliary Iminodiacetic Acid (HIDA) Scan. In StatPearls online. StatPearls Publishing. 2019.

11. Shah I, Bhatnagar S, Rangarajan V, Patankar N. Utility of Tc99m-Mebrofenin hepato-biliary scintigraphy (HIDA scan) for the diagnosis of biliary atresia. Trop Gastroenterol. 2012;33(1):62-4.

12. Kianifar HR, Tehranian S, Shojaei P, Adinehpoor Z, Sadeghi R, Kakhki VRD et al. Accuracy of hepatobiliary scintigraphy for differentiation of neonatal hepatitis from biliary atresia: systematic review and meta-analysis of the literature. Ped rad. 2013;43(8):905-19.

13. Shuman WP, Gibbs P, Rudd TG, Mack LA. PIPIDA scintigraphy for cholecystitis: false positives in alcoholism and total parenteral nutrition. Am $\mathbf{J}$ of Roent. 1982;138(1):1-5.

Cite this article as: Afzal M, Ali SM, Khairy AT, Khattabi M, Shahid F, Ramzee AF, Ahmed K. Hepatobiliary scintigraphy and its clinical implications: mini review. Int Surg J 2021;8:766-70. 